\title{
APRESENTAÇÃO
}

\section{Dossiê A sociologia da religião hoje: secularização(ões), secularismo(s) ou laicidade?}

Carlos Eduardo Sell' Helena Vilaça ${ }^{2}$ Jorge Botelho Moniz ${ }^{3}$

Dedicado a Peter L. Beger (1929-2017)

1. O objetivo deste dossiê, ainda que não desconsidere a importância do empírico, é confrontar crítica e teoricamente algumas das principais abordagens gerais de estudo do fenômeno religioso nas sociedades contemporâneas, sintetizadas em torno de três problemáticas centrais: secularização, secularismo e laicidade.

A proposta de debater e confrontar estas diferentes perspectivas teóricas surgiu a partir da realização do I Colóquio Internacional Estudos de laicidade: conceitos, modelos e desafios, realizado pelo Programa de Pós-Graduação em Sociologia Política da Universidade Federal de Santa Catarina (UFSC), entre os dias 1 e 2 de setembro de 2015 e que, além dos professores da UFSC - Carlos Eduardo Sell e Amurabi Pereira de Oliveira - , contou ainda com a participação de estudiosos da religiáo de outras universidades brasileiras - Ricardo Mariano - Universidade de São Paulo (USP), Raquel Weiss - Universidade Federal do Rio Grande Sul (URGS) e

Universidade Federal de Santa Catarina.

2 Universidade do Porto.

3 Universidade Nova de Lisboa e Universidade Federal de Santa Catarina. 
Luís Antônio Cunha - Universidade Federal do Rio de Janeiro (UFRJ) - e de pesquisadores de outros países - Helena Vilaça (Universidade do Porto) e Eduardo Weisz (Universidade de Buenos Aires).

Dos estimulantes debates realizados em Florianópolis SC resultou a conclusão de que, além da ideia de laicidade, a sociologia da religiáo contemporânea é marcada por uma grande pluralidade de pontos de vista, razão pela qual, além desse conceito, a meta desta coletânea consiste também em apresentar, problematizar e comparar criticamente enfoques analíticos que partem das categorias da secularização e do secularismo. Fundamental para as intençôes desta compilação é fornecer um quadro analítico atualizado e plural que não só contemple algumas das tendências teóricas mais recentes e centrais (ainda que sem compromisso com a exaustividade), mas que, ao mesmo tempo, expresse a diversidade de olhares sobre a relação entre religião e mundo moderno. Isso justifica nosso esforço para integrar ao projeto contribuiçóes de pesquisadores de diversos países, incluindo, além do Brasil, Alemanha, Arábia Saudita, Argentina, Estados Unidos, Itália, Portugal, Reino Unido ou Suíça. Deste esforço de articulação, resulta um dossiê no qual estão incluídos alguns dos mais importantes e influentes cientistas sociais da religiấo do cenário nacional e internacional.

Em seu conjunto, o(a) leitor(a) encontrará aqui um dossiê que, sem qualquer opção teórica a priori e respeitando as diferenças, debate, em nível global, o estado da arte da discussão sobre a sociologia da religião contemporânea. Portanto, não é o caso de, no curto espaço dessa apresentação, ensaiar um panorama teórico geral sobre este tema, substituindo, de forma redundante, o que acaba sendo feito, dos mais diversos ângulos, ao longo dos artigos aqui reunidos. Não obstante, cabe-nos ao menos justificar e explicar por que razão os conceitos de laicidade, secularização e secularismo foram escolhidos como termos-chave e guias analíticos capazes de - segundo nosso entendimento dar-nos acesso ao estado da rica e polêmica discussão teórica e empírica que se desenrola atualmente na área da sociologia da religião. Em que medida eles nos permitem captar e avaliar criticamente as principais tendências em curso?

2. Laicidade e secularização são conceitos que nos remetem aos nossos pais fundadores, tanto em relaçáo à disciplina de sociologia em geral, quanto 
à área temática da sociologia da religiáo, em particular. Confrontados com o desafio de pensar a relação entre a gênese da modernidade e seus desdobramentos na esfera religiosa, Émile Durkheim e Max Weber desenvolveram aportes teóricos que, como atesta a perenidade destes dois conceitos clássicos, ainda hoje são matrizes decisivas para compreender o estatuto do religioso na contemporaneidade. Apesar de suas diferenças metodológicas, resultado em especial da ênfase na dimensão coletiva (Durkheim) ou individual (Weber), podemos divisar também importantes semelhanças na distinção sagrado-profano e cotidiano e extracotidiano [Alltäglichkeit x Äusseraltäglichkeit] que estão na base da definição do fenômeno religioso em cada um deles (SCHLUCHTER, 1991). Ambos estavam também de acordo quanto ao fato de que o processo de diferenciação social (segundo Durkheim) ou de desencantamento do mundo (segundo Weber) implicava essencialmente a transformação do estatuto do religioso em condiçôes modernas. Contudo, apesar das similaridades, é claro que não se tratam de perspectivas idênticas, o que nos obriga a considerar alguma das suas especificidades.

Não seria possível entender por que Durkheim, retomando os temas da religião civil de Jean-Jacques Rousseau, lançou mão da concepção de laicidade, sem nos reportarmos ao contexto das tensóes e disputas que ela engendrou na França dos inícios do século XX. Elaborada no bojo dessa disputa política, a laicidade deve ser entendida, prima facie, como um conceito regulativo (PORTIER, 2011), ainda que ela nos permita, em nível empírico, identificar e examinar diferentes regimes institucionais de regulação política do religioso (GIUMBELLI, 2012). Todavia, para além do aspecto descritivo-classificatório, qual é realmente seu potencial sociológico-explicativo? Ademais, devido ao seu componente essencialmente normativo, não surpreende que a França contemporânea venha sendo o palco de uma intensa disputa em torno da semântica deste conceito, postulando-se em torno dele versôes mais radicais ou mais moderadas do reconhecimento e da inserção da religião na esfera pública, como ilustrou, recentemente, a interessante controvérsia entre Jean-Paul Willaime e Jean Baubérot (2011).

Já o conceito de secularização de Weber, cujo interesse na religiáo, por sinal, é posterior ao Kulturkampft (promovido por Bismarck), não é utilizado para determinar normativamente um modelo institucional de relação religião-política, mas para explicar (paradoxalmente) como a religião é o veículo de 
saída da religião, utilizando aqui a emblemática expressão de Marcel Gauchet (1985). A secularização designa, assim, um grande processo macro-histórico marcado tanto pela ruptura quanto pela continuidade (SELL, 2015), pois a modernidade, na mesma medida em que impulsiona a transição de um horizonte cultural transcendente para um quadro cultural imanente, não deixa de reproduzir, ainda que em forma mundana, o racionalismo da dominação do mundo. A sua lógica intrínseca se transfere para as ordens sociais e para o modo de vida ativo do indivíduo moderno (como ilustra a metamorfose da ética protestante em ética capitalista).

Apesar de a religião ser um tema incontornável para os sociólogos fundadores, eles foram essencialmente influenciados pelo Iluminismo e pela crítica racionalista. Comte, Marx e Freud, que revelam uma animosidade nítida em relação à religião, vêem-na como um obstáculo à análise científica da sociedade (WILSON, 1988; WILLAIME, 1995). Muito embora as posturas teóricas de Weber e Durkheim se demarcassem das perspectivas mais escatológicas da religião, a verdade é que a influência de certo tipo de análise marxista se repercutiu no reducionismo e na marginalização da sociologia da religiáo em uma boa parte do século XX.

O contributo mais significativo de Marx para a sociologia da religiáo diz respeito à sua crítica política e filosófica da religião. Em Marx, a religião surge como ópio do povo em uma acepção alusiva à opressão, logo alienação da realidade, em um processo de perda de consciência do indivíduo em relação ao mundo em que se insere. $\mathrm{O}$ fato de o marxismo atribuir à religiáo, enquanto fenômeno localizado na superestrutura, um papel secundário nesta tradição sociológica, a religião não é vista como um fator de mudança estrutural ou de emancipação humana (RIIS, 1999) - refletiu-se fortemente no modo como uma boa parte dos sociólogos perspectivou a religião ao longo do século XX: fizeram-no segundo um modelo muito reducionista, contribuindo ainda para o reconhecimento tardio da religião enquanto área autônoma de saber sociológico.

Assim, o desenvolvimento e a consolidação da reflexão sociológica foram negligenciando a religião, fato que também se explica pelo impacto das teorias da secularização. Apesar disso, a sociologia foi parcialmente resolvendo sua tensão com a religiáo, passando a apresentar o declínio religioso como 
um processo sociológico e não como algo panfletário (WILSON, 1988). Foi abandonada progressivamente a tese de que a sociologia seria uma fonte alternativa de prescrição para a ordem social. Desse modo, a reabilitação da religião na teoria sociológica passou, entre outros aspectos, pela já citada releitura de Durkheim e Weber. À medida que a sociologia da religião se institucionaliza como área autônoma desta ciência (em particular ao longo do pós-segunda Grande Guerra), a temática da secularização acabou se hegemonizando, principalmente através dos trabalhos de Wilson (1969 [1966]), Berger (1990 [1967]) e Luckmann (1967). Em boa medida, as diversas perspectivas desenvolvidas no âmbito daquela problemática foram demasiadamente marcadas pelo neofuncionalismo e pela sociologia cognitiva, acabando por dar origem a certa marginalização dos estudos sociológicos sobre religiâo no seio da disciplina. Por outro lado, as teorias da secularização tiveram como realidade de referência as sociedades europeias, centrando-se na perda da influência social da religião e no declínio das representaçôes religiosas, devido à racionalização funcional e ao desencantamento do mundo, tal como Weber tinha vaticinado.

Principalmente a partir das décadas de 1980 e 1990, o modelo da secularização começa a ser alvo de críticas mais sistematizadas. Por um lado, sociólogos estadunidenses como Stark e Bainbridge (1985) ou Finke (1997) começam a interpretar o fenômeno de revitalização religiosa como uma faceta da sociedade moderna. Apoiados na teoria da escolha racional e analisando a formação de cultos e seitas e sua proliferação na sociedade, encaram a secularização como um processo limitativo. Estes autores entendem que a teoria da escolha racional é particularmente adequada para explicar a fragmentação e diversidade religiosa contemporâneas, pautadas por uma lógica de oferta e procura. Por outro lado, por conta das novas dinâmicas do religioso, surgem outras críticas à secularização relacionadas com a questão dos novos movimentos religiosos (BARKER, 1995) e, de uma forma mais genérica, com as reconfiguraçóes do universo religioso em um quadro social cada vez mais globalizado. Os trabalhos sobre a crescente individualização das crenças e do sentimento religioso (CHAMPION; HERVIEU-LÉGER, 1990; DAVIE, 1994), a difusão do sagrado nas diferentes instâncias da realidade (HAMMOND, 1985) e as espiritualidades nova era e seculares (HEELAS; WOODHEAD, 2005) alargariam o campo de reflexão acerca das novas formas de religiosidade, no contexto de secularização, multiplicando as produçóes no campo da sociologia da religiáo. 
Essas interpretaçóes quanto ao lugar presente e futuro das religiōes nas sociedades modernas levaram os acadêmicos a acomodar o novo fenômeno dentro dos conceitos de ressurgimento do sagrado (BELL, 1977), desprivatização ou repolitização do religioso (CASANOVA, 1994), dessecularização (BERGER, 1999) ou pós-secularização (HABERMAS, 2008). Embora expliquem o processo por meio de perspectivas diferentes, os autores ora elencados e suas teorias pretendem descrever a perenidade e preeminência pública das religióes e sua compatibilidade, ainda que atribulada, com as sociedades hodiernas. Por conta dessa evolução teórica, as análises empíricas voltaram-se recente e progressivamente para a análise do secularismo (CADY; HURD, 2010), isto é, as relaçôes institucionalizadas e juridicamente codificadas entre Estado e religião e que têm como base algum tipo de separação entre as esferas temporal e espiritual. Segundo Casanova (2011), a análise e interpretação deste conceito é hoje incontornável, porque, contrariamente ao conceito clássico de secularização, não assume qualquer desenvolvimento histórico progressivo que converterá a religião em uma dimensão social insignificante. Pelo contrário, o secularismo é compatível com uma perspectiva positiva da religião, encerrando diferentes formas ou padróes democráticos de relação Estado, religião e sociedade (KURU, 2009; STEPAN, 2011).

A maior sensibilidade teórica atual no reconhecimento dos diferentes percursos políticos, sociais e religiosos - para a qual muito contribuíram a análise genealógica do secular de Asad (2003) e a perspectiva da secularização como uma história de subtração de Taylor (2007) - evidencia uma aproximação aos debates atuais sobre a teoria da modernidade, nomeadamente à abordagem das múltiplas modernidades (EISENSTADT, 2000). Aqui se afirma que o mundo contemporâneo é um espaço de (re)constituição contínua de diferentes programas da modernidade e admite-se a influência de atores ou circunstâncias regionais específicas (forças políticas ou econômicas, ativistas ou movimentos sociais, a mídia ou os fenômenos migratórios), com perspectivas não unívocas, sobre a reconstrução dos padrôes de relação Estado, sociedade e religiáo na modernidade. Isso levou os autores a desenvolver conceitos como múltiplas secularizaçóes (MARTIN, 2005; DEMERATH, 2007), múltiplos secularismos (STEPAN, 2011), múltiplas secularidades (WOHLRAB-SAHR; BUCHARDT, 2012) ou a renovar seu interesse nas diferentes fronteiras da laicidade (GIUMBELLI, 2012). 
Perante toda esta multiplicidade de expressões religiosas, políticas e sociais, Peter Berger, que desde a década de 1990 vem revendo seu tópico original, entende o pluralismo, e não a secularizaçáo, como o tema central na sociologia da religiáo (BERGER, 2014). Para tanto, na análise dos fenômenos religiosos contemporâneos, são cada vez mais necessárias novas grades analíticas, tal como sugerido por Martikainen e Gauthier (2013): nova economia, mercado, mídia, migraçôes estão entre as forças nucleares. Assim, contrariamente às ideias que postulavam (e algumas ainda postulam, relembre-se, por exemplo, Steve Bruce) que as instituiçóes e as práticas religiosas tendem a entrar em persistente e consistente declínio, atualmente o fator a ser explicado parece ser a mutação do religioso em condiçôes modernas e não o seu declínio (VILAÇA, PACE, FURSETH \& PETTERSSON, 2014).

3. Do raciocínio aqui exposto, podemos inferir - em esforço de grande síntese - que o cenário teórico da sociologia da religiáo encontra-se, hoje, cindido entre abordagens que, conforme a tradição clássica, privilegiam a relação entre religião e sociedade (caso especial das teorias da secularização e de seus críticos) ou aquelas que deslocam esta ênfase na direção do binômio religiâo e política (como parece ser o caso em se tratando de laicidade ou secularismo). Estaria a sociologia contemporânea da religiấo a viver um momento de retorno do político ou estaria este cenário a exigir um retorno ao social? Afinal, por onde anda e por onde deveria caminhar o discurso teórico em sociologia da religiáo?

Em vez de respondê-las, a candência destas indagaçóes nos servem como a deixa perfeita para que passemos a expor as linhas gerais dos trabalhos que compóem esta coletânea, pois é neles que estas questóes centrais recebem formulaçóes e matizes que nos permitem, de fato, buscar algumas respostas.

Para efeitos de sistematização dos trabalhos aqui compilados, dividimos o dossiê em três partes essenciais. Tal como a epígrafe desta introduçáo denuncia - por sua proeminência e influência nas análises sobre o lugar da religião nas sociedades modernas -, na primeira parte elencam-se as reflexóes teóricas sobre a secularização e, em seguida, os trabalhos que abordam esta temática através de uma perspectiva mais teórico-empírica. Na segunda parte, coligimos os artigos de autores que abordam o secularismo por intermédio de 
processos de pesquisa teórico-empíricos. Por fim, mais sucintamente, disporemos os autores que analisam, aprofundam e problematizam o tópico da laicidade.

Apesar de nem todos os artigos da primeira seção, assim como das outras (relativamente ao tema do secularismo e da laicidade), deste número temático desenvolverem explicitamente o modelo da secularização, todos eles, sem exceção, seguem a tradição das discussóes por ela encetadas e desenvolvidas. Nesse sentido, o dossiê se inicia com um amplo panorama histórico-sociológico sobre a modernidade e sobre o modo como ela pode ser compreendida como uma nova cultura axial. Com efeito, o trabalho de Wolfgang Schluchter (Universidade de Heidelberg) permite-nos considerar quais os diferentes contextos em que a correlação entre modernidade e secularização está posta no cenário contemporâneo. Na esteira de Schluchter, Carlos Eduardo Sell (UFSC) procura retomar a teoria das modernidades múltiplas para, a partir dela, desdobrar a possibilidade de pensar sobre a multiplicidade da secularização. Enquanto Schluchter e Sell, seguindo de perto a tradição weberiana, oferecem-nos amplos quadros históricos e analíticos sobre o tema da secularização, o trabalho de Jorge Botelho Moniz (UFSC e Universidade Nova de Lisboa) mergulha nos críticos, propondo uma perspectiva plural da(s) teoria(s) da secularização(óes) e analisando suas cinco críticas-tipo. Ao traçar as limitações proposicionais da secularização, o autor ajuda a enquadrar as novas categorias analíticas e/ou empíricas propostas em seguida por Eduardo Weisz (Universidade de Buenos Aires), Donizete Rodrigues (Universidade da Beira Interior) e Monika Wohlrab-Sahr (Universidade de Leipzig) e Marian Burchardt (Max Planck Institute). O primeiro coloca o problema da des ou pós-secularização a partir de Weber; ou seja, problematiza a questão da racionalização na modernidade avançada mediante uma abordagem weberiana. O segundo fala do erro de Nietzsche. A partir da releitura dos autores clássicos e modernos da sociologia da religiáo, Donizete Rodrigues desenvolve a ideia de desencantamentodo mundo e analisa a (nova) dinâmica - individualizada, desterritorializada, plural e diversa - da religião na sociedade contemporânea. Os últimos, focando-se nas distinçóes entre as esferas e práticas sociais religiosas e não religiosas e nas variadas possibilidades de institucionalização dessas distinçóes, revisitam o conceito de secular e propóem, por meio da 
ideia de múltiplas secularidades, uma nova perspectiva para as trajetórias da modernidade.

Dentro de uma esfera mais teórico-empírica da secularização, elencamos um quinteto de artigos. $\mathrm{O}$ primeiro, de Brand Arenari (UENF), à luz da tradição weberiana de alguns dos artigos precedentes, procura mapear os impedimentos históricos e ideológicos do protestantismo e do pentecostalismo (brasileiro). Com Steve Bruce (Universidade de Aberdeen), não só o tema da secularização é teoricamente aprofundado e problematizado, em especial seus pressupostos universalizantes, mas também se retoma a discussão sobre o caso brasileiro e a expectativa de que, em face às mutaçôes nacionais, a modernização enfraqueça a religião. Mantendo o foco no continente americano, Paul Christopher Manuel (American University) analisa as teorias da reação cultural e da insegurança econômica - subsidiárias do modelo da secularização - para compreender a eleição estadunidense de 2016. Dentro de uma perspectiva mais cultural, próxima da ideia de secularidade de Wohlrab-Sahr e Burchardt, Alfredo Teixeira (Universidade Católica Portuguesa) propóe a observação da deslocação do sagrado através dos novos lugares - criação musical contemporânea - em que estão sendo construídas as atuais relaçóes entre o religioso e os outros mundos sociais. Para encerrar esta seção, Gert Pickel (Universidade de Leipzig) oferece um exame empírico abrangente dos recentes índices de secularização europeus, mas não somente, sobretudo ao nível individual, advogando que o modelo clássico da secularização continua tendo corroboração empírica mesmo perante a crescente influência da religiáo na política.

O binômio religiáo-política - o secularismo - tem destaque na segunda seção deste dossiê temático. Para efeitos de esclarecimento sobre as problemáticas e as dinâmicas da competição entre o religioso e o secular, encontramos o trabalho de Jörg Stolz e Pascal Tanner (Universidade de Lausanne) que nos oferece os elementos básicos para entendermos a hodierna relação entre essas duas esferas. Os casos empíricos aí analisados (seis, entre eles: Suíça, Estados Unidos e Irlanda) permitem-nos uma análise mais informada dos textos seguintes. Com efeito, Mark Juergensmeyer (Universidade da Califórnia), ao analisar o ataque ao Charlie Hebdo (2015), à luz do problema do terrorismo, reflete de forma detalhada e sistematizada sobre o secularismo moderno e sobre sua guerra imaginada com a religião. Talal Asad (City University de Nova Iorque) faz, no artigo mais longo deste compêndio, um esforço analítico 
semelhante, interpretando as complexas imbricaçôes entre tradição, religião e política no Egito pós-revolução de 2011. O tópico do secularismo é arrematado com o texto de Enzo Pace (Universidade de Pádua) no qual se aprofunda ainda mais a sobreposição entre religiáo e política - a sacralização do secular dos movimentos etnofundamentalistas no Sri Lanka e na Índia.

No final do nosso dossiê tem espaço o debate sobre a laicidade. Não obstante a discussão sobre esta temática seja mais sucinta (o que nos parece, por sinal, sintomático da ascensão da perspectiva do secularismo sobre a da laicidade), ela é bastante rica e atual. Destacamos o texto de Raquel Weiss (UFRGS) que trabalha mais sobre a questão teórica da laicidade, resgatando e reinterpretando o interesse de Durkheim para os teóricos da secularizaçáo, nomeadamente para os interessados no pluralismo e nas teorias pós-seculares da modernidade tardia. Por fim, o artigo de Amurabi Pereira de Oliveira (UFSC) retoma a questão da laicidade, mas com um cunho mais teórico-empírico, investigando a relação entre Estado e religião no Brasil. Em particular, a interligação religião-educação, à luz da lei da Bíblia, em Florianópolis/SC (2015) e sua questão teórica subjacente: a ampliação semântica do conceito de laicidade. $\mathrm{O}$ seu trabalho mostra, portanto, que o conceito de laicidade, mais que um instrumento analítico, é um termo disputado no debate público, chamando-nos à atenção para o devido cuidado no trânsito entre uma realidade e outra.

Feita a devida introdução dos trabalhos ora colecionados, resta-nos desejar que o(a) leitor(a), em face ao nosso esforço de abrangência teórica e empírica, interdisciplinaridade e internacionalização deste número temático sobre a sociologia da religião hoje, considere suas leituras tão informativas e frutuosas quanto foram para nós, organizadores deste dossiê, ao longo dos últimos meses de organizaçáo do no 36, maio/agosto 2017, da Política \& Sociedade.

Como última palavra, gostaríamos de fazer nosso agradecimento público à equipe da revista Política \& Sociedade, nas pessoas dos seus editores Ernesto Seidl e Marcia da Silva Mazon e de suas bolsistas Elis Rodrigues e Tsamiyah Levi.

\section{Referências}

ASAD, T. Formations of the Secular: Christianity, Islam, Modernity. Stanford: Stanford University Press, 2003. 
BARKER, E. New Religious Movements: A Practical Introduction. London: MSO, 1995.

BAUBÉROT, J. A favor de uma sociologia intercultural e histórica da laicidade”, Civitas: Revista de Ciências Sociais, v. 11, n. 2, p. 284-302, 2011.

BELL, D. The Return of the Sacred?. British Journal of Sociology, v. 28, n. 4, p. 419-449, 1977.

BERGER, P. The Sacred Canopy: Elements of a Sociological Theory of Religion. Garden City, Nova Jérsia: Doubleday, [1967] 1990.

The Desecularization of the World, a Global Overview. In: (Ed.). The

Desecularization of the World: Resurgent Religion and World Politics. Michigan: Grand Rapids, 1999. p. 1-18.

The Many Altars of Modernity: Toward a Paradigm for Religion in a Pluralist Age. Boston/Berlim: De Gruyter, 2014.

CADY, L.; HURD, E. S. Comparative Secularism and the Politics of Modernity: An Introduction. In: CADY, L.; HURD, E. S. (Ed.). Comparative Secularism in a Global Age. New York: Palgrave Macmillan, 2010. p. 3-24.

CASANOVA, J. Public Religions in the Modern World. Chicago: University of Chicago Press, 1994.

The secular, secularizations, secularisms. In: CALHOUN, C.; JUERGENSMEYER, M.; ANTWERPEN, J. (Ed.). Rethinking Secularism. New York: Oxford University Press, 2011. p. $54-74$.

CHAMPION, F.; HERVIEU-LÉGER, D. (Dir.). De l'emotion en religion. Paris: Éditions du Centurion, 1990.

DAVIE, G. Religion in Britain since 1945: Believing without Belonging. Oxford: Wiley Blackwell, 1994.

DEMERATH, J. Secularization and Sacralization, Deconstructed and Reconstructed In: BECKFORD, J.; DEMERATH, J. (Ed.). The Sage Handbook of the Sociology of Religion. Londres: Sage Publications, 2007. p. 57-80.

EISENSTADT, S. Multiple modernities. Daedalus, v. 129, n. 1, p. 1-30, 2000.

FINKE, R. The Consequences of Religious Competition: Supply-side Explanations for Religious Change. In: YOUNG, L. A. (Ed.), Rational Choice Theory and Religion: Summary and Assessment. New York/London: Routledge, 1997, p. 45-64. 
GAUCHET, M. Le désenchantement du monde. Une histoire politique de la religion. Gallimard: Paris, 1985.

GIUMBELLI, E. Fronteiras da laicidade. Revista Brasileira de Ciências Sociais, v. 27, n. 79, p. 205-208, 2012.

HABERMAS, J. Between Naturalism and Religion: philosophical essays. Trad. Ciaran Cronin, Cambridge: Polity, 2008.

HAMMOND, P. E. (Ed.). The Sacred in the Secular Age. Berkeley: University of California Press, 1985.

HEELAS, P.; WOODHEAD, L. The Spiritual Revolution. Why Religion is Giving Way to Spirituality. Oxford: Blackwell, 2005.

KURU, A. T. Secularism and State Policies toward Religion. Cambridge: CUP, 2009.

LUCKMANN, T. The Invisible Religion: The Problem of Religion in Modern Society. New York: Macmillan, 1967.

MARTIKAINEN, T.; GAUTHIER, F. Religion in the Neoliberal Age: Political Economy and Modes of Governance. Farnham: Ashgate, 2013.

MARTIN, D. On secularization: Towards a revised general theory. New York: Routledge, 2005.

MOEBIUS, S. Pos-estructuralismo e ciências sociales. In: TOLEDO, E. G.; LEYVA, G. (Org.). Tratado de metodologia: perspectivas atuales. México: Fondo de Cultura Econômica, 2012. p. 525-566.

PORTIER, P. A regulação estatal da crença nos países da Europa Ocidental. Religiáo \& Sociedade, v. 31, n. 2, p. 11-28, 2011.

RIIS, O. (1999). Modes of Religious Pluralism under Conditions of Globalisation. IJMS: International Journal on Multicultural Societies, v. 1, n.1, 1999, pp. 20-34.

SCHLUCHTER, W. Religion und Lebensführung, vol. 1. Suhrkamp; Frankfurt a. M.: Studienausgabe, 1991.

SELL, C. E. A secularização como sociologia do moderno. Max Weber, a religião e o Brasil no contexto moderno-global. Revista Brasileira de Sociologia, São Paulo, v. 3, n. 6, p. 11-46, 2015.

STARK, R. S.; BAINBRIDGE, W. S. The Future of Religion: Secularization, Revival and Cult Formation. Los Angeles: University of California Press, 1985. 
STEPAN, Alfred. The multiple secularisms of democratic and non-democratic regimes. In: CALHOUN, C.; JUERGENSMEYER, M.; ANTWERPEN, J. (Ed.). Rethinking Secularism. New York: Oxford University Press, 2011. p. 114-144.

TAYLOR, C. A Secular Age. Cambridge: Harvard University Press, 2007.

VILAÇA, H.; PACE, E.; FURSETH, I.; PETTERSSON, P. The Changing Soul of Europe. Religions and Migrations in Northern and Southern Europe. Farnham: Ashgate, 2014.

WILLAIME, J-P. Sociologie des religions. Paris: Presses Universitaires, 1995.

WILSON, B. [1966]. Religion and Secular Society. A sociological comment. Londres: C. A. Watts \& Co, 1969.

Religion in Sociological Perspective. Oxford-New York: Oxford University Press, 1988.

WOHLRAB-SAHR, M.; BUCHARDT, M. "Multiples Secularities: Toward a cultural sociology of secular modernities. Comparative Sociology, v. 11, p. 875-909, 2012. 